\title{
Use of Silica Tubes as Nanocontainers for Corrosion Inhibitor Storage
}

\author{
Cesia Ávila-Gonzalez, ${ }^{1}$ Rodolfo Cruz-Silva, ${ }^{1}$ Carmina Menchaca, ${ }^{1}$ \\ Selene Sepulveda-Guzman, ${ }^{2}$ and Jorge Uruchurtu ${ }^{1}$ \\ ${ }^{1}$ CIICAp, Universidad Autonoma del Estado de Morelos, Avenida Universidad 1001, Col. Chamilpa, Cuernavaca 62209, MOR, Mexico \\ ${ }^{2}$ CIDIT, Universidad Autonoma de Nuevo Leon, Avenida Alianza 101 Sur, Apodaca, Monterrey 66455, NL, Mexico
}

Correspondence should be addressed to Carmina Menchaca, cmenchaca@uaem.mx

Received 12 May 2011; Revised 12 July 2011; Accepted 15 July 2011

Academic Editor: Abdel Salam H. Makhlouf

Copyright () 2011 Cesia Ávila-Gonzalez et al. This is an open access article distributed under the Creative Commons Attribution License, which permits unrestricted use, distribution, and reproduction in any medium, provided the original work is properly cited.

A new alkyd paint anticorrosion smart coating was developed by using silica nanoparticles as corrosion inhibitor nanocontainers. Silica particles were mixed with the paint at different concentrations to study their performance and ensure their free transportation to the damaged metal. The filling up of silica particles was done preparing three solutions: distilled water, acetone, and a mixture of both, with $\mathrm{Fe}\left(\mathrm{NO}_{3}\right)_{3}$ and silica particles immersed in each of the solutions to adsorb the inhibitor. Acetone solution was the best alternative determined by weight gain analysis made with the inhibitor adsorbed in silica nanocontainers. Steel samples were painted with inhibitor silica nanocontainer coatings and immersed in an aqueous solution of $3 \%$ sodium chloride. Polarization curves and electrochemical noise techniques were used to evaluate the corrosion inhibitor system behavior. Good performance was obtained in comparison with samples without inhibitor nanocontainer coating.

\section{Introduction}

Every corrosive protection action effort may be lost or become more costly if the mechanisms are effective but not efficient and/or applied in an area ill prepared or under nonideal conditions. So it is necessary to develop new avant garde design schemes to achieve effective protection. Currently, smart coating applied in nanotechnology promise solutions to this problem and benefits everything from new applications, existing structures under more efficient solution. Storage of the inhibitor is based on the use of particles, which can play the role of nanocontainers for corrosion inhibitors adsorbed inside [1-3].

A new generation of anticorrosion coatings that respond to changes in the environment has sparked great interest because corrosion is one of the most important causes of destruction of structures that involve the loss of material, and prevention is paramount. This type of protection is intended to retard corrosion of the metal substrate and/or control it. In this paper, a smart system for corrosion protection was developed based on the synthesis of silica $\left(\mathrm{SiO}_{2}\right)$ nanotubes and the storage and containment of ferric nitrate $\left(\mathrm{Fe}\left(\mathrm{NO}_{3}\right)_{3}\right)$ as an oxidant corrosion inhibitor, mixed in a polymer coating to achieve a "smart inhibitor coating" performance. The coating releases the active ions, which act as a local trigger mechanism inhibiting or passivating the active metal surface, when it is required. The direct introduction of components of the protective coating inhibitor often leads to the deactivation of the corrosion inhibitor and polymer matrix degradation. To overcome these, it is desirable to study several systems that trap the inhibitor preventing their direct interaction with the coating matrix, and it is the main subject of this paper. The concept of this coating is as follows: the scale of the containers is of nanometer dimensions, so these are filled with a corrosion inhibitor. When these nanocontainers are for instance mechanically deformed or the metal surface is corroding, the inhibitor is released slowing down as a passive layer formed over the surface which interacts with the electrochemical reaction.

The oldest types of self-repairing coatings are polymerbased coatings. These micrometer-scale containers, filled 
with monomers similar in nature to the polymer matrix and an appropriate catalyst initiating the polymerization of the monomer when released at the damaged spot of the polymer coating are incorporated inside the coating matrix. When these microcontainers become mechanically deformed, they release the monomer and catalyst and thus seal the defect [4-7].

Polyelectrolyte-based aqueous poly(L-lysine)-graft-poly (ethylene glycol) was employed as the self-healing agent. The barrier properties of a damaged coating can also be repaired by a simple blocking of the defects with insoluble precipitates. Another approach to hybrid self-healing coatings is based on the use of inhibitors that can be released from the coating system $[8,9]$.

Several systems entrapping the inhibitor and preventing its direct interaction with the coating matrix have been developed. One, quite simple, approach to inhibitor entrapment is based on the complexation of organic molecules by cyclodextrin [10]; another is based on the use of oxide nanoparticles, which can play the role of nanocontainers for corrosion inhibitors adsorbed on their surface. The inhibition of inorganic ions can also be incorporated by exchangeable ions associated with cation- and anion-exchange solids. For anion-exchange solids, the release of inhibitor anions can be provoked by aggressive corrosive chloride ions [11-13].

The most important aspect in the design of new active coatings is to make nanocontainers that have good compatibility with the matrix components that can encapsulate and maintain the active material and that possess a shell with permeability properties that can be controlled by external stimuli. Several approaches have been developed so far to fabricate micro- and nanocontainers [14-20].

The next step in the fabrication of nanocontainers suitable for self-repairing anticorrosion coatings is to make nanocontainer shells sensitive to the corrosion process, or another external trigger, in order to activate the release of the encapsulated inhibitor species. The mechanism of these shelled nanocontainers is the smart self-healing process. Nanocontainers should be able to regulate the storage/release of an inhibitor $[18,21]$.

Therefore it is proposed, a polymer coating system which consists of an alkyd paint containing silica nanoparticles filled with corrosion inhibitor. These silica nanoparticles containers are "tubes" sized $0.8 \times 0.2$ microns, forming hundreds of parallel channels of $\sim 5 \mathrm{~nm}$ in diameter. Filling the inside of the nanotubes with $\left(\mathrm{Fe}\left(\mathrm{NO}_{3}\right)_{3}\right)$ as corrosion inhibitor; this system acts as a corrosion protective coating barrier achieving a "smart" paint system, containing inhibitor released from these particles when the coating is damaged. The performance of this "intelligent" system, nanotube-inhibitor-coating applied on carbon steel samples immersed in chloride solution, was evaluated using electrochemical techniques.

\section{Experimental Procedure}

2.1. Procedure for Synthesis of Silica Nanoporous SBA-15. The synthesis of nanoporous material SBA-15 was made using
Pluronic 123, as template, and TEOS (tetraethyl orthosilicate reagent grade, 98\%), as silica precursor. Pluronic 123 is an AB-A triblock copolymer surfactant that has been widely used in the synthesis of nanoporous silica. It consists of hydrophobic polypropyleneoxide block and hydrophilic polyethyelen oxide and is represented by the formula $\mathrm{HO}\left(\mathrm{CH}_{2} \mathrm{CH}_{2} \mathrm{O}\right)_{20}$ $\left(\mathrm{CH}_{2} \mathrm{CH}\left(\mathrm{CH}_{3}\right) \mathrm{O}\right)_{70}\left(\mathrm{CH}_{2} \mathrm{CH}_{2} \mathrm{O}\right)_{20} \mathrm{OH}$. The synthesis process is described as follows: $24 \mathrm{~g}$ of Pluronic 123 were dissolved in $756 \mathrm{~mL}$ of distilled water and $121 \mathrm{~mL}$ of $\mathrm{HCl}$ $37 \mathrm{wt} \%$ were added, the reaction mixture was heated and stirred at $750 \mathrm{rpm}$ and $400^{\circ} \mathrm{C}$, adding immediately $55 \mathrm{~mL}$ of TEOS and leaving under stirring for $25 \mathrm{~min}$. Then, agitation was stopped maintaining a temperature of $400^{\circ} \mathrm{C}$ for $24 \mathrm{~h}$, allowing for hydrolysis and the formation of nanostructure. Finally, a heat treatment in air at $900^{\circ} \mathrm{C}$ for 48 hours was carried out. At the end of heat treatment, the SBA-15 nanoparticles were washed, filtered, and dried in an oven at $60^{\circ} \mathrm{C}$ for $8 \mathrm{~h}$.

2.2. Agglomeration of Particles. The agglomeration of solid silica within the alkyd resin was observed; different weight percentage $(2.5 \%, 5 \%, 7.5 \%$, and $10 \%)$ particles were mixed with a commercial transparent alkyd varnish which was used as coating. This mixture of uniform thickness was film deposited on glass plate objects to study their agglomeration in the optical microscope, their roughness in the AFM, and its dispersion in the stereoscope.

2.3. Filling of Particles with Inhibitor. For the filling up of nanocontainers, three solutions were prepared up to $8 \%$ $(80 \mathrm{mg} / \mathrm{ml})$ of ferric nitrate $\left(\mathrm{Fe}\left(\mathrm{NO}_{3}\right)_{3}\right)$, the first with distilled water, the second with $1: 3$ acetone: distilled water ratio, and the third with acetone only. Silica particles were immersed in each of the solutions to achieve maximum particles weight gain by the presence of the inhibitor. The formation of seals on the ends of the nanocontainer is based on the reaction between the inhibitor loaded and the transition $\mathrm{Fe}$ metal ions that brings insoluble complexes of ferric nitrate distributed at the ends of the nanotube containers to act as seals or stoppers.

2.4. System Characterization of Silica SBA-15 and Steel Surface. Different characterization techniques were used during this work including Olympus GX71 optical and Motic Digital DM143 stereoscopic microscopy, scanning electron microscope SEM LEO 1450VP, atomic force microscopy AFM Nanoscope IV Digital Instruments, and transmission electron microscopy TEM FEI Titan3 G2. These were done in order to observe the structure of the nanotubes, the adsorption of the inhibitor, and the coating system characteristics. After sixteen days of exposure to the saline solution, samples were removed and observed in the optical microscope in order to see the corrosion attack of the metal surface and corroborate the performance of the "intelligent" silica inhibitor coating system.

2.5. Electrochemical Cell Preparation. Electrochemical tests were performed in a $3 \% \mathrm{NaCl}$ solution prepared using 
analytical reagent grade chemicals $(\mathrm{NaCl})$ and distilled water at room temperature. For testing, two $500 \mathrm{~mL}$ beakers were used as electrochemical cells: one for nanotube inhibitor container coating electrodes, the other for comparison as a coating without inhibitor samples. Two "identical" working electrodes, a graphite auxiliary electrode, and a calomel reference electrode were used throughout the experiments.

2.6. Electrode Preparation. The material tested was carbon steel encapsulated in a commercial MC-40 resin. Rectangular probes were cut and an exposed area of $1 \mathrm{~cm}^{2}$ to the solution were used. All of them were abraded up to $600 \mathrm{SiC}$ emery paper and finished to a "mirror-" like using alumina paste rinsed with distilled water and ethanol. The polymer (alkyd varnish) matrix or protective coating, that acts as a barrier on the metal surface (carbon steel), was mixed with silica nanotubes filled with the corrosion inhibitor, and then applied to the steel metal surface using a small brush. Alternatively, metal samples were prepared using the varnish without the silica tubes, as a protective coating for comparison purpose. After nine days of immersion, samples were scratched over the coating surface with the sharpened tip of a glass tube, instead of a metallic cutter, to avoid galvanic effects. This was done to simulate "in service" coating damage and provoke corrosion conditions to evaluate the performance of the smart inhibitor coating system under damaging conditions. This is a common procedure in corrosion passive film and coating evaluation [22].

2.7. Electrochemical Measurements. The electrochemical free corrosion potential of the working electrode, $E_{\text {corr }}$, was measured using a saturated calomel reference electrode (SCE), triplicate electrochemical measurements were obtained with a fully computerized potentiostat and the average values were registered. Polarization tests were performed with 2.5, 5, 7.5, and $10 \%$ of silica particles containing inhibitor mixed in paint. Potentiodynamic polarization curves were also used to characterize electrochemical properties of the tested materials. The potentiodynamic sweep was from $-800 \mathrm{mV}$ to $-200 \mathrm{mV}$ with a rate of $100 \mathrm{mV} / \mathrm{min}$ using an $\mathrm{ACM}$ instrument and software.

Electrochemical noise measurements (EN) in both current and potential were recorded using two identical working electrodes and a reference electrode (SCE). The electrochemical noise measurements were made recording simultaneously the potential and current fluctuations at a sampling rate of one point per second for a period of 1024 seconds. A fully automated zero resistance ammeter (ZRA) from ACM instruments was used. Removal of the DC trend from the raw noise data was the first step in the noise analysis when needed, because this could originate large distortions in subsequent statistical data processing [22-24]. To accomplish this, trend removal of the signal by least square fitting method and Hanning windowing was performed. Finally, the noise resistance $R_{n}$ inversely proportional to the corrosion rate was calculated as the ratio of the potential noise standard deviation over the current noise standard deviation

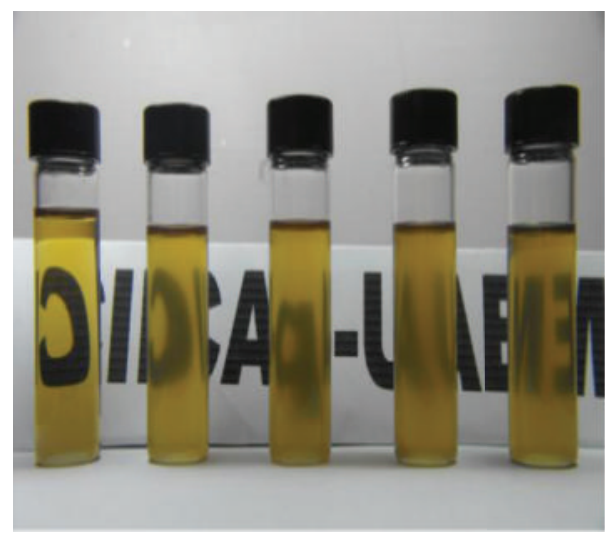

Figure 1: Coating mixtures containing silica particles at different percentages $(0,2.5,5.0,7.5$, and $10 \%)$ showing transparency conditions.

$\left(R_{n}=\sigma_{v} / \sigma_{i}\right)$. Commercial software (Origin 5.0) was used to perform a frequency analysis by an FFT (Fast Fourier Transform) algorithm. In this way, the noise impedance power spectral density (PSD) in the frequency domain was obtained.

\section{Results and Discussion}

3.1. System Characterization. Figure 1 presents the different silica nanocontainers concentration and coating mixtures reflecting the agglomeration and dispersion of the silica particles in the paint. The color changes from a light yellow to a darker one as a function of particle content.

Under certain circumstances, coating transparency is paramount and Figure 1 presents the various silica-concentration coatings. Here, transparency decreases as a function of concentration, although remaining quite transparent for the highest concentration as the letters in the background of the photograph gives evidence.

Figures 2(a) and 2(b) present the TEM images for SBA-15 silica particles, with curved form tubes $0.8 \times 0.2$ microns in size, forming a parallel ordered channel system of approximately $\sim 5 \mathrm{~nm}$ in diameter. They have an hexagonal uniform structure and well-defined long tubes. Figures 2(c) and 2(d) present TEM micrographs of the silica particles immersed in the inhibitor dissolved in acetone, where the greatest weight gain was observed. It can be seen that most of the pores of SBA-15 are darker due to inhibitor adsorption within the pores. Over the particle surface, the inhibitor is anchored on the external channels, therefore, being suitable to act as a container and be mixed with the paint coating to form the smart system.

Table 1 presents the silica particles with different percent of inhibitor content and mixture preparation.

Figure 3 presents the SEM micrograph obtained for a nanoporous particle exposed to the ambient temperature without being dried. Notice that after water adsorption, particles tend to agglomerate to form SBA-15 silica particle chains, forming a curved tube. 


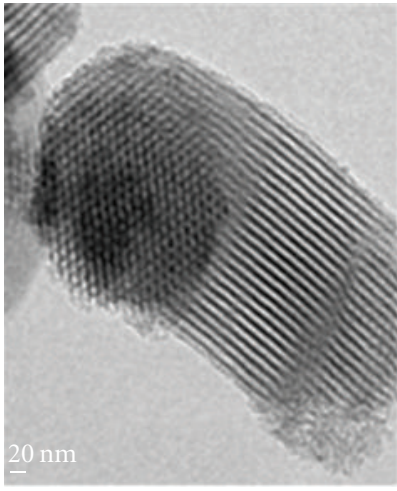

(a)

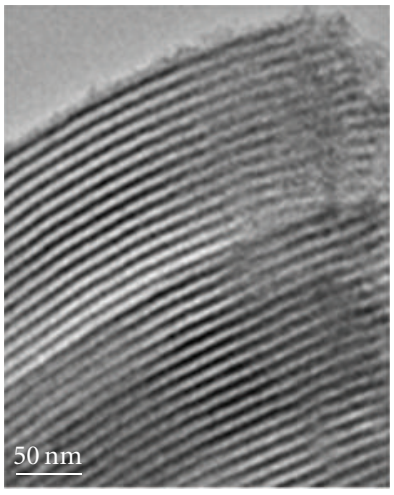

(b)

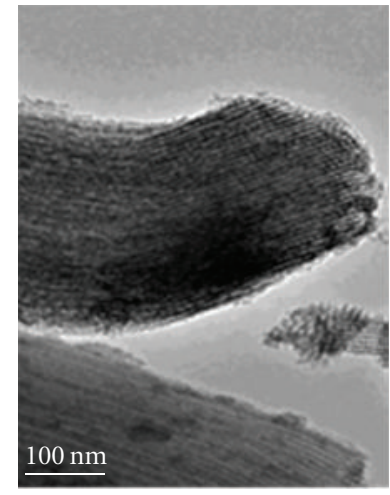

(c)

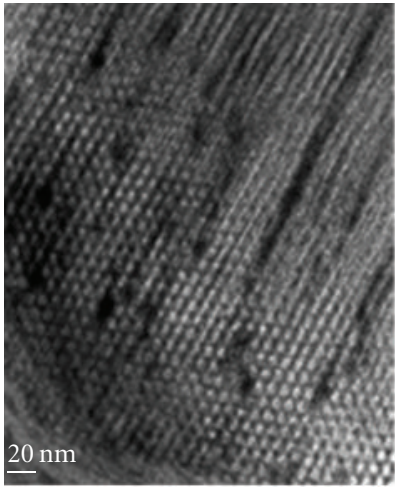

(d)

FIgURE 2: TEM images for SBA-15 silica particles without inhibitor (a) general view, (b) higher magnification, containing inhibitor (c) general view, (d) higher magnification.

TABLE 1: Silica particles and inhibitor content preparation.

\begin{tabular}{lcccc}
\hline Percent solids & Silica $(\mathrm{g})$ & Inhibitor $(\mathrm{g})$ & Silica + inhibitor $(\mathrm{g})$ & Inhibitor $(\mathrm{ppm})$ \\
\hline $2.5 \%$ & 0.0010 & 0.0015 & 0.0025 & 1.5 \\
$5.0 \%$ & 0.0019 & 0.0031 & 0.0050 & 3.1 \\
$7.5 \%$ & 0.0028 & 0.0047 & 0.0075 & 4.7 \\
$10 \%$ & 0.0038 & 0.0062 & 0.0100 & 6.2 \\
\hline
\end{tabular}

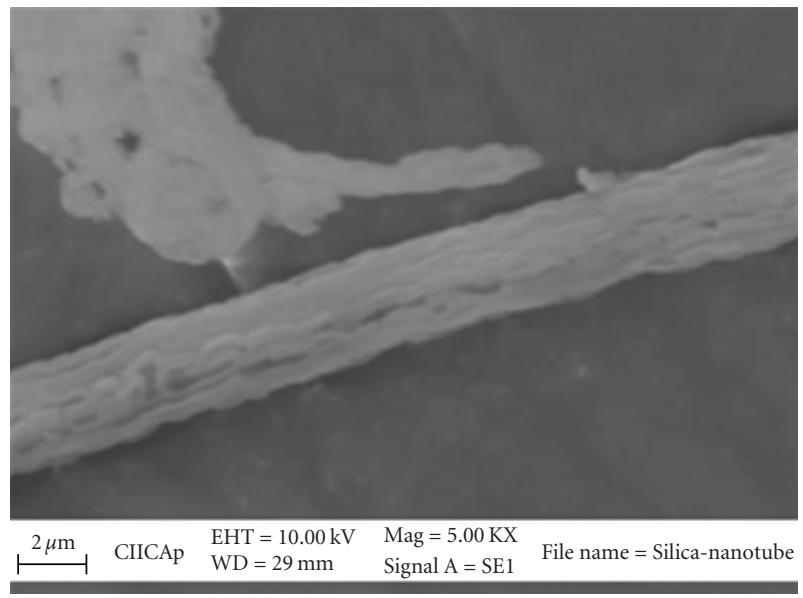

FIGURE 3: SEM micrograph showing the agglomerated silica nanotube.

Figure 4 presents the optical micrograph (5X) obtained for the coating paint without and with $2.5 \%$ up to $10 \%$ silica particle system. Figure 4(a) presents the paint without silica particles, where a good dispersion of the coating over the surface can be observed.

The $2.5 \%$ silica particle concentration presents a rough surface due to the presence of SBA-15 particles, with a slight agglomeration in small quantities and good coating dispersion (Figure 4(b)). For the 5 and $7.5 \%$ silica particle content, an increasingly rough surface and higher agglomeration can be observed (see Figures 4(c) and 4(d)), with a fair dispersion of the paint and particles over the surface.
The $10 \%$ content presents a highly rough-painted surface and very noticeable agglomerates, implying an almost nil dispersion of the particles, as can be seen in Figure 4(e).

Figure 5 presents the $10 \mathrm{X}$ magnification stereoscopic micrographs, showing the presence of SBA-15 nanoporous particles as bright points over the paint. A gradual increase in dispersion can be observed, as solids content grow with the increasing percentage presence of SBA-15 in the mixture.

Table 2 shows the weight gain of the nanoporous silica immersed in three solutions with ferric nitrate: distilled water, 1:3 distilled water to acetone ratio, and acetone alone. Note that the highest gain was obtained for the ferric nitrate solution with acetone after 3 cycles. After 72 hours of immersion, the percent weight gain was $61.78 \%$, after acetone evaporation [2].

Figure 6 presents AFM images obtained for the paint including 5\% nanoporous silica particles (without inhibitor, Figure 6(a)), and with particles containing inhibitor (Figure 6(b)). The figures reveal the roughness coating surface present for the two different conditions. The particles without inhibitor coating AFM spectrum present a slightly rough surface with a few cracks formed due to bubble formation while the coating was being applied to the sample. In general, it can be said that the coating surface is smooth and became rougher for the coating containing $5 \%$ inhibitor nanocontainer. The surface profile shows this condition (Figure 6(b)). The peaks indicate agglomeration of particles and good cohesion amongst them due to higher solid content.

3.2. Electrochemical Measurements. To cover the surface of the $1 \mathrm{~cm}^{2}$ mild steel electrode used for electrochemical tests, 


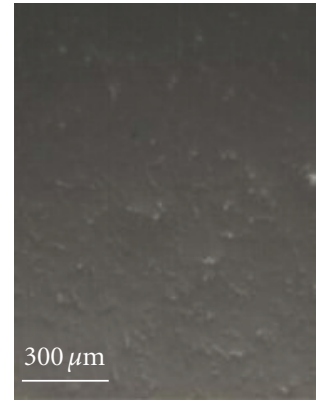

(a)

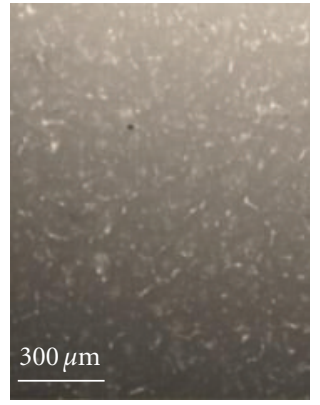

(b)

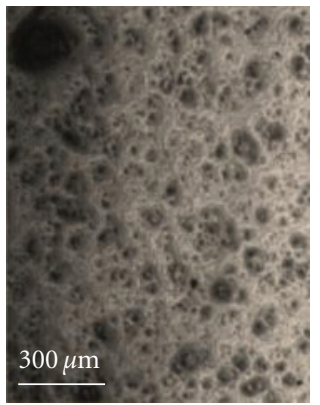

(c)

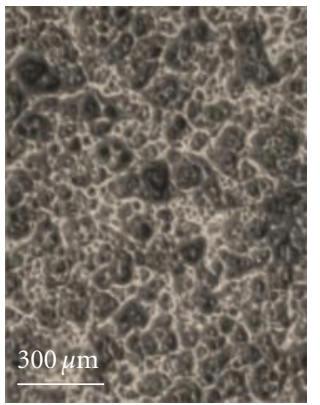

(d)

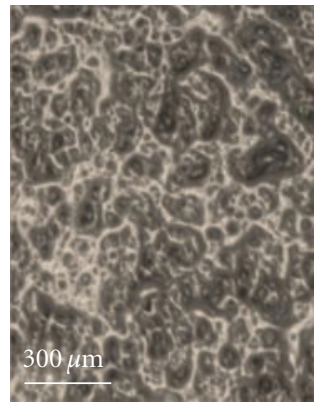

(e)

FIGURE 4: Optical microscopy micrographs showing surface conditions for the coating paint (a) without particles, (b) $2.5 \%$, (c) 5.0\%, (d) $7.5 \%$, and (e) $10 \%$ silica particle content system, (5X).

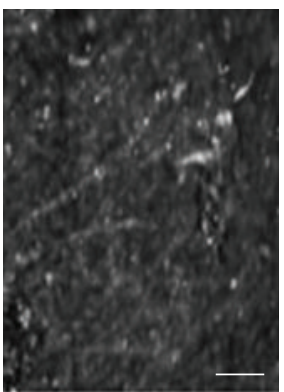

(a)

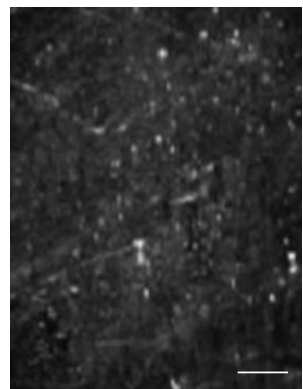

(b)

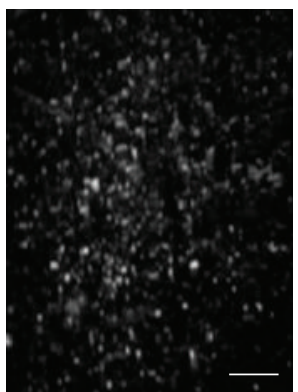

(c)

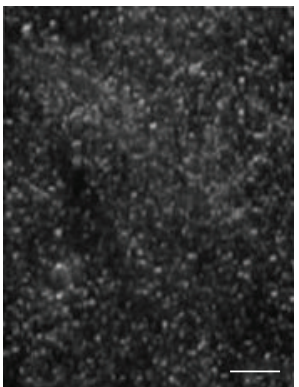

(d)

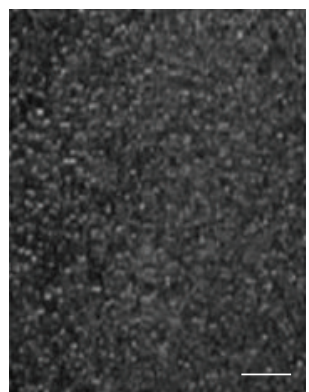

(e)

FIGURE 5: Stereoscopic microscopy micrographs showing the presence of nanoporous SBA-15 particles over the coating paint (a) without particles, (b) $2.5 \%$, (c) $5.0 \%$, (d) $7.5 \%$, and (e) $10 \%$ silica particles content system (10X, bar scale $300 \mu \mathrm{m}$ ).

TABLE 2: Weight gain of the inhibitor contained nanoporous silica particle.

\begin{tabular}{lccc}
\hline Sample & Solution & Solids weight & Weight gain \\
\hline 1 & $\mathrm{Fe}\left(\mathrm{NO}_{3}\right)_{3}+\mathrm{H}_{2} \mathrm{O}$ & $0.1632 \mathrm{~g}$ & $0.0222 \mathrm{~g}$ \\
2 & $\mathrm{Fe}\left(\mathrm{NO}_{3}\right)_{3}+\mathrm{H}_{2} \mathrm{O}+$ acetone & $0.2404 \mathrm{~g}$ & $0.0994 \mathrm{~g}$ \\
3 & $\mathrm{Fe}\left(\mathrm{NO}_{3}\right)_{3}+$ acetone & $0.3180 \mathrm{~g}$ & $0.1770 \mathrm{~g}$ \\
\hline Sample & Solution & Solids weight & Weight gain \\
\hline 1 & $\mathrm{Fe}\left(\mathrm{NO}_{3}\right)_{3}+\mathrm{H}_{2} \mathrm{O}$ & $0.1674 \mathrm{~g}$ & $0.0264 \mathrm{~g}$ \\
2 & $\mathrm{Fe}\left(\mathrm{NO}_{3}\right)_{3}+\mathrm{H}_{2} \mathrm{O}+$ acetone & $0.2439 \mathrm{~g}$ & $0.1029 \mathrm{~g}$ \\
3 & $\mathrm{Fe}\left(\mathrm{NO}_{3}\right)_{3}+$ acetone & $0.3208 \mathrm{~g}$ & $0.1798 \mathrm{~g}$ \\
\hline Sample & $\mathrm{Solution}_{3}$ & Solids weight & Weight gain \\
\hline 1 & $\mathrm{Fe}\left(\mathrm{NO}_{3}\right)_{3}+\mathrm{H}_{2} \mathrm{O}$ & $0.1702 \mathrm{~g}$ & $0.0292 \mathrm{~g}$ \\
2 & $\mathrm{Fe}\left(\mathrm{NO}_{3}\right)_{3}+\mathrm{H}_{2} \mathrm{O}+$ acetone & $0.2695 \mathrm{~g}$ & $0.1285 \mathrm{~g}$ \\
3 & $\mathrm{Fe}\left(\mathrm{NO}_{3}\right)_{3}+$ acetone & $0.3690 \mathrm{~g}$ & $0.2280 \mathrm{~g}$ \\
\hline
\end{tabular}

a $5 \%$ nanocontainers containing inhibitor was mixed with the paint, and $0.1 \mathrm{~g}$ of this coating was then used. Different inhibitor concentrations $1.5,3.1,4.7$, and 6.2 ppm contained in the silica particles, were prepared (see Table 1), and painted samples were tested in a $3 \% \mathrm{NaCl}$ solution, which was then used for the polarization curves, as seen in Figure 7.

From the polarization curves, it can be seen that the corrosion potential around $-550 \mathrm{mV}$ for the sample without inhibitor is moved approximately $100 \mathrm{mV}$ in the anodic direction. The active corrosion potentials were $-570 \mathrm{mV}$ without inhibitor, $-670,-690,-685$, and $-680 \mathrm{mV}$ for the different inhibitor concentrations. The inhibitor is working on the anodic branch, producing corrosion products and a passivation region of the metal (carbon steel). These can be seen in the corrosion rates calculated. The cathodic branch presents a current limit region due to oxygen reduction, which was also modified with the presence of the inhibitor.

The corrosion rate $\left(i_{\text {corr }}\right)$ decreases in solutions of painted samples containing 1.5, 3.1, 4.7, and $6.2 \mathrm{ppm}$ of inhibitor with respect to the test without inhibitor [2]. The current density corrosion rates were $2.74 \mathrm{~mA} / \mathrm{cm}^{2}$ without inhibitor, down to $2.57,2.09,2.12$, and $2.25 \mathrm{~mA} / \mathrm{cm}^{2}$, respectively. Therefore, the best inhibitor performance was found at $3.1 \mathrm{ppm}$ concentration condition. This inhibitor concentration was tested throughout the rest of the electrochemical experiments.

The corrosion potential as a function of time is presented in Figure 8, for the mild steel samples with alkyd coating without particles, with $5 \%$ silica nanoparticles containing $3.1 \mathrm{ppm}$ inhibitor concentration. Bear in mind the surface was scratched the ninth day, to promote corrosion.

The free corrosion potential for the sample without inhibitor presents active potentials and is becoming more anodic or active as a function of time. The ninth day it remains almost the same, showing the same trend. On the contrary, the sample with inhibitor presents more positive 

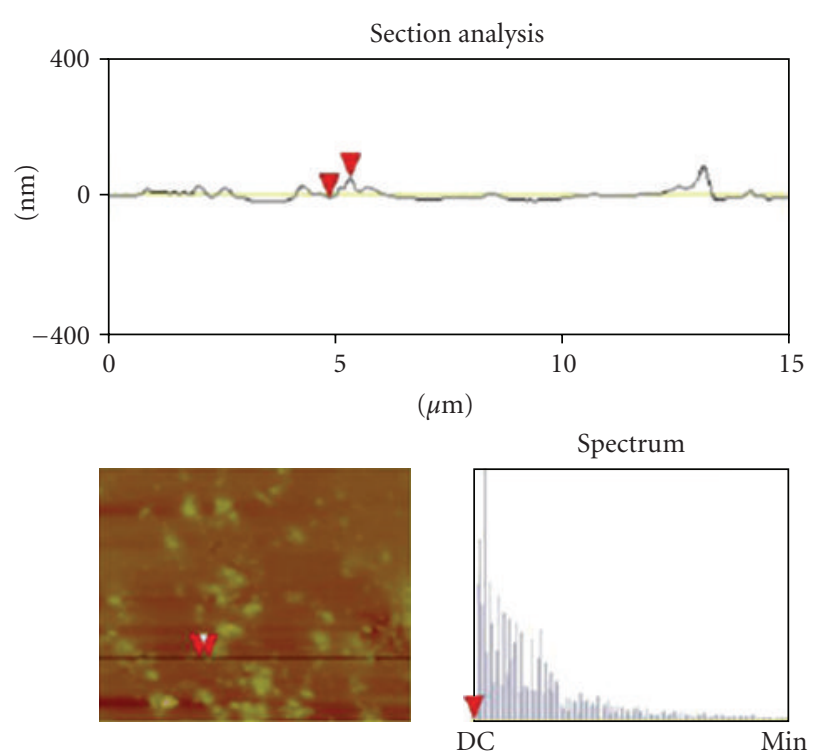

(a) 5\% nanocontainer without inhibitor
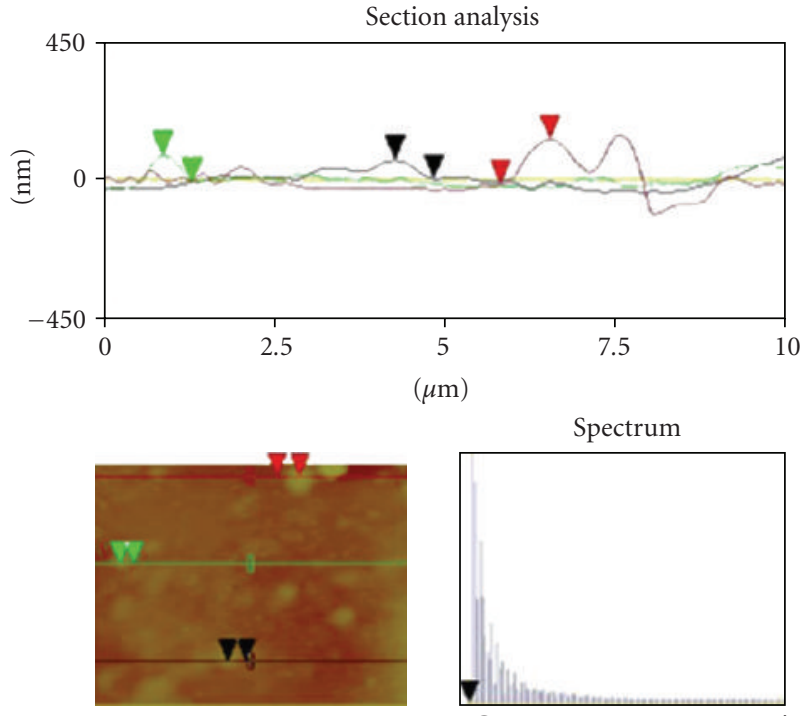

(b) $5 \%$ nanocontainer with inhibitor

FIGURE 6: AFM spectrum obtained for the coating and 5\% nanocontainer (a) without inhibitor and (b) with inhibitor.

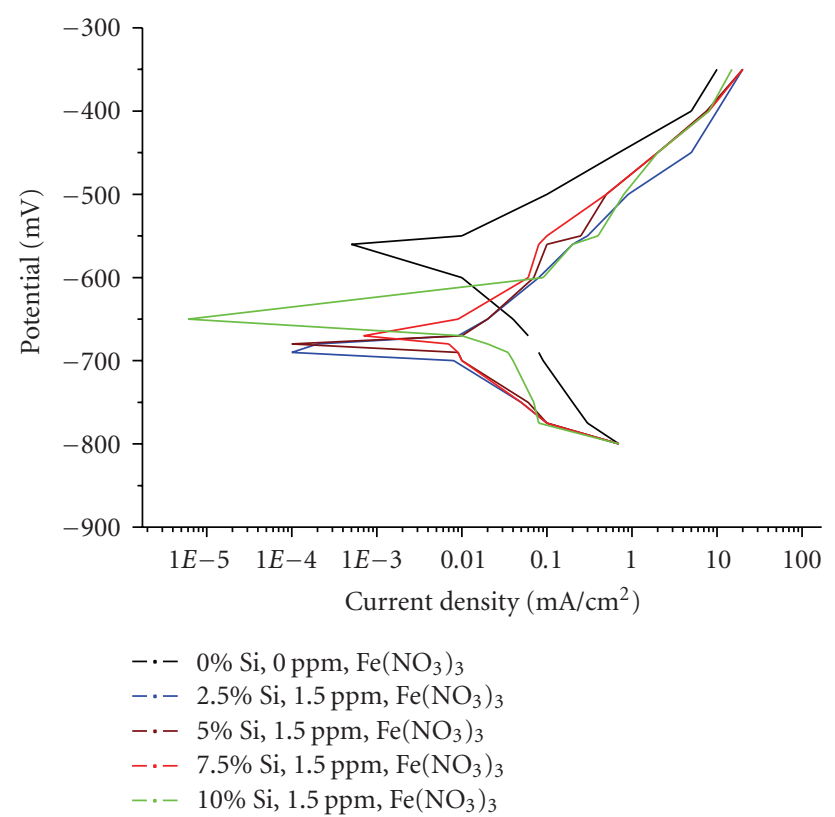

FIGURE 7: Polarization curves for mild steel in chloride solution (a) coating without particles, (b) $2.5 \%$, (c) $5.0 \%$, (d) $7.5 \%$, and (e) $10 \%$ silica nanoparticles with different $\mathrm{Fe}\left(\mathrm{NO}_{3}\right)_{3}$ inhibitor concentration.

potentials, although with a similar trend in the anodic direction. After scratching the surface, the potential became more positive and started to decrease again. This behavior is related to the quality of the coating and in the presence of the inhibitor, after scratching the surface, the inhibitor promotes corrosion and oxide formation, which is shown as an increase in potential.

Electrochemical noise measurements for the coating nanocontainer inhibitor system were performed to observe

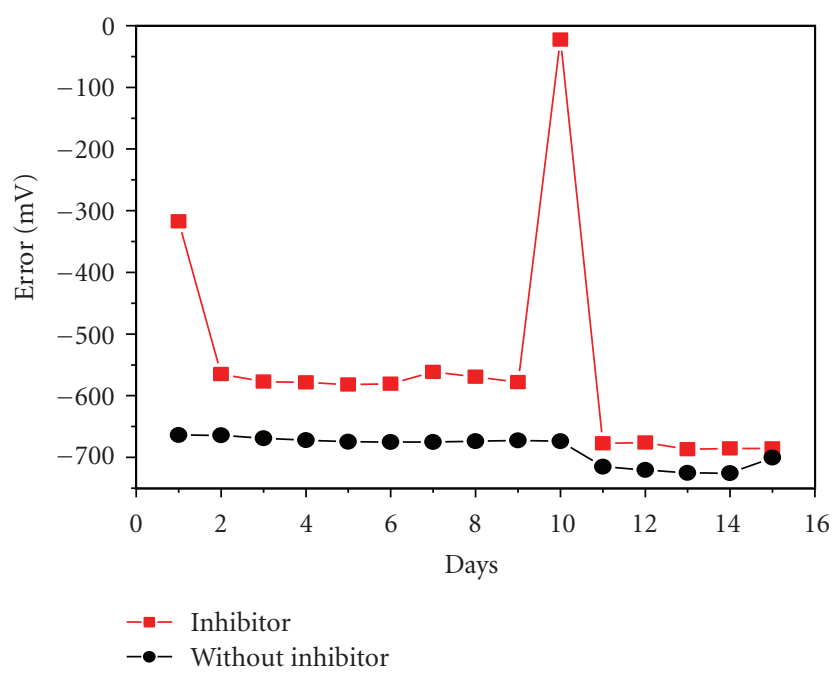

FIGURE 8: Corrosion potential as a function of time for mild steel alkyd coated without nanoparticles, and with $5 \%$ containing $3.1 \mathrm{ppm} \mathrm{Fe}\left(\mathrm{NO}_{3}\right)_{3}$ inhibitor concentration.

the corrosion behavior as a function of time. Figure 9 presents the electrochemical noise resistance as a function of time, obtained from the electrochemical potential noise divided over the electrochemical current noise time series obtained for each of the sixteen days of immersion $[25,26]$.

In general, the noise resistance obtained for the coating silica containing inhibitor remained two orders of magnitude higher compared to the noninhibitor condition. Being the noise resistance inversely proportional to the corrosion rate 


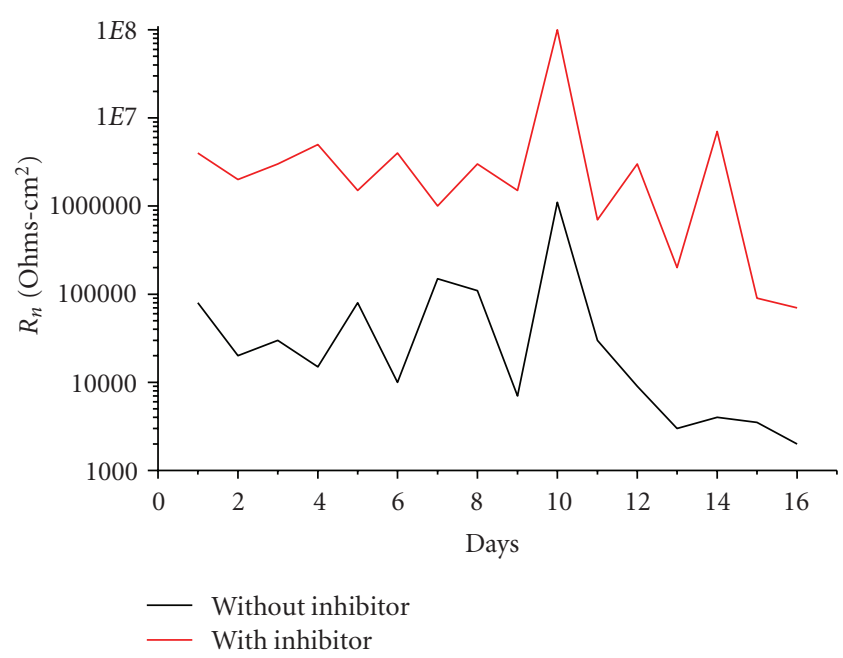

Figure 9: Noise resistance as a function of time for mild steel alkyd coated without nanoparticles, and with $5 \%$ silica particles containing $3.1 \mathrm{ppm} \mathrm{Fe}\left(\mathrm{NO}_{3}\right)_{3}$ inhibitor concentration.

means the inhibitor sample corrodes one hundred times less than the sample coated without the inhibitor. The variability observed throughout the experiment for both conditions, could be associated to the permeation of water through the coating and the oxygen diffusion condition promoting the attack. Also the presence of chloride ions promotes localized attack over the metal surface. The ninth day, the sample surface was scratched to promote corrosion before the measurement and the noise resistance values obtained were lower.

Nevertheless, the noise resistance was higher for the sample with the inhibitor compared to the inhibitor sample without it, this suggests the protective action of the inhibitor in the presence of the corrosive attack. The following day, the formation of corrosion products over the scratch for both metal samples increased the noise resistance value again, registering the maximum value obtained throughout the experiment. The trend to decrease the noise resistance in both cases could be due to the coating degradation and the increase in the corrosion conditions; but the difference in resistance values for both systems remained, because of the inhibitor action, until the end of the experiment.

The electrochemical noise resistance behavior is reflected in the power noise impedance spectra obtained from the frequency analysis. It is presented in Figure 10 for different times of immersion [27-29]. Higher values were always obtained for the coating containing inhibitor stored particles. The difference in the spectra observed of the inhibitor sample condition and the noninhibitor coating one is clear. Figure 10(a) corresponds to the samples immersed after 24 and 72 hours, showing higher values at one day of immersion. Figure 10(b) presents the ninth and tenth days of immersion spectra (the day of the scratch and one day after), where the power noise impedance spectra diminishes the day of the scratch, increasing again the day after. This was due to corrosion and subsequent oxide formation the day after, but the behavior between the two conditions remained throughout the test. After 10 and 11 days of immersion (Figure 10(c)) the spectrum corresponding to the noninhibitor condition reached levels similar to those corresponding to the inhibitor content condition. Finally, at the end of the experiment after 300 and 360 hours of immersion, the behavior observed throughout the experiment remained. Higher power noise impedance values for the inhibitor samples, therefore lower corrosion rates promoted by the corrosion inhibitor action $[27,28]$.

The noise resistance equivalent to the polarization resistance parameter (obtained through other electrochemical techniques) represents the sum of all the resistances of the system. The noise impedance accounts for the pores resistance of the low-barrier paint or protective coating. The pore resistance can be attributed to the noise resistance when (i) the coating exhibits porosity presenting diffusion mechanism as the rate-determining step, and (ii) when the sampling frequency of the recorded data gives a Nyquist frequency close to $1 \mathrm{~Hz}[26,30]$.

In these results, the steep slopes obtained by the power noise impedance spectra, and the cathodic branch presented by the polarization curves (see Figure 7), suggest diffusion control $[26,29]$.

After sixteen days of immersion in the chloride solution, the electrode condition is the metal sample painted without inhibitor and scratch shows pitting corrosion over the surface (Figure 11(a)), due to paint degradation and lack of inhibitor agent. The scratched surface suffered localized attack over the scratch and corrosion products are easily visible (Figure 11(b)) from the direct action of aggressive species accelerating corrosion.

Nevertheless, the electrode coated with the paint containing silica nanocontainers and inhibitor without scratch over the surface (Figure 11(c)) is protected. Few areas with some corrosion products over the surface of the metal substrate, probably due to the presence of the inhibitor, are observed. The scratched surface (Figure 11(d)) presents some corrosion products over the edges of the scratch with no visible delamination of the coating, probably from the action of the oxidant inhibitor [30].

The corrosion coatings system proposed here presents excellent performance $\left(\mathrm{Rn} \sim 1 \mathrm{E} 7 \mathrm{ohms}-\mathrm{cm}^{2}\right)$ compared to epoxy coating, according to the electrochemical noise measurements reported previously in the literature $[26,28]$.

\section{Conclusions}

A smart corrosion control system of mild steel in chloride neutral solution was developed. This consists in a mixed coating with silica nanocontainers acting as inhibitor containers. The best experimental conditions were coatings with $5 \%$ silica particles and $3.1 \mathrm{ppm} \mathrm{Fe}\left(\mathrm{NO}_{3}\right)_{3}$. The electrochemical tests show the performance of both the inhibitor and the active ingredient, silica particles acting as nanocontainer particles that release and retard the corrosion of the metal. The action of the system decreased the corrosion rate almost 


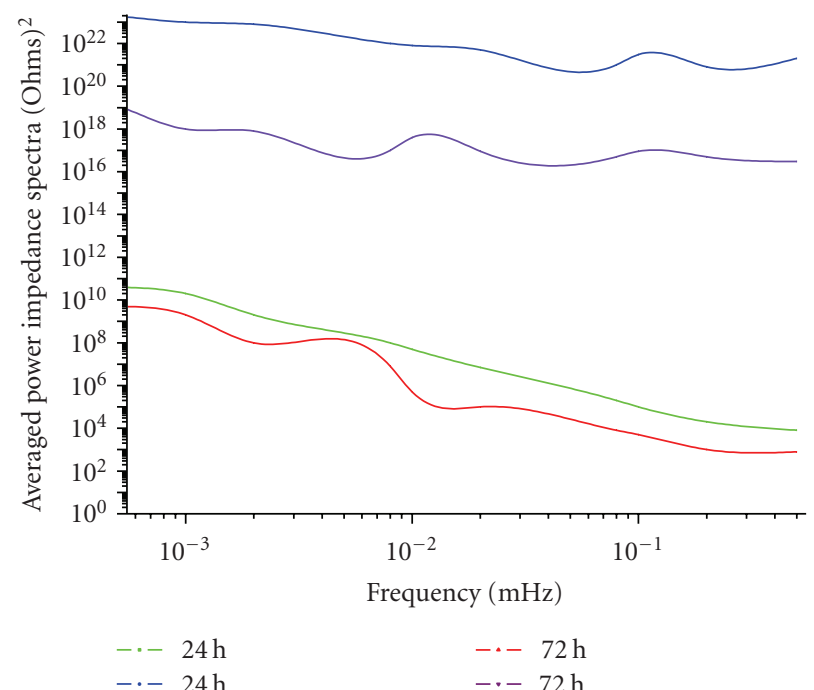

(a) 24 and $72 \mathrm{~h}$

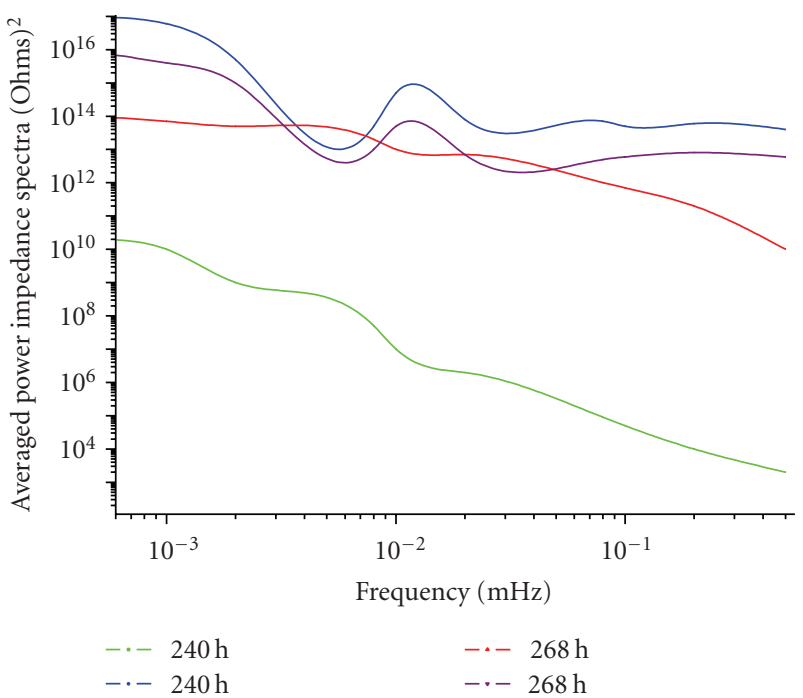

(c) 240 and $268 \mathrm{~h}$

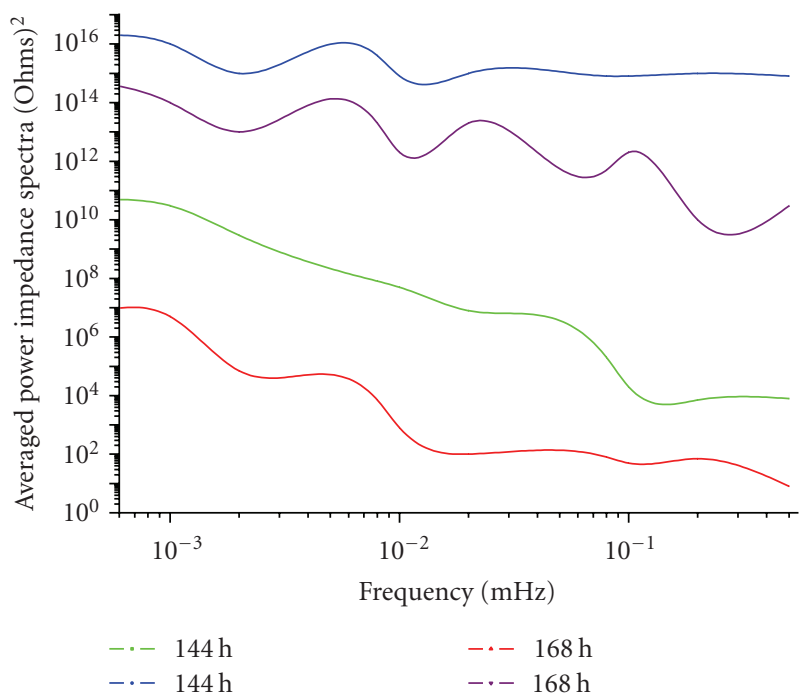

(b) 144 and $168 \mathrm{~h}$

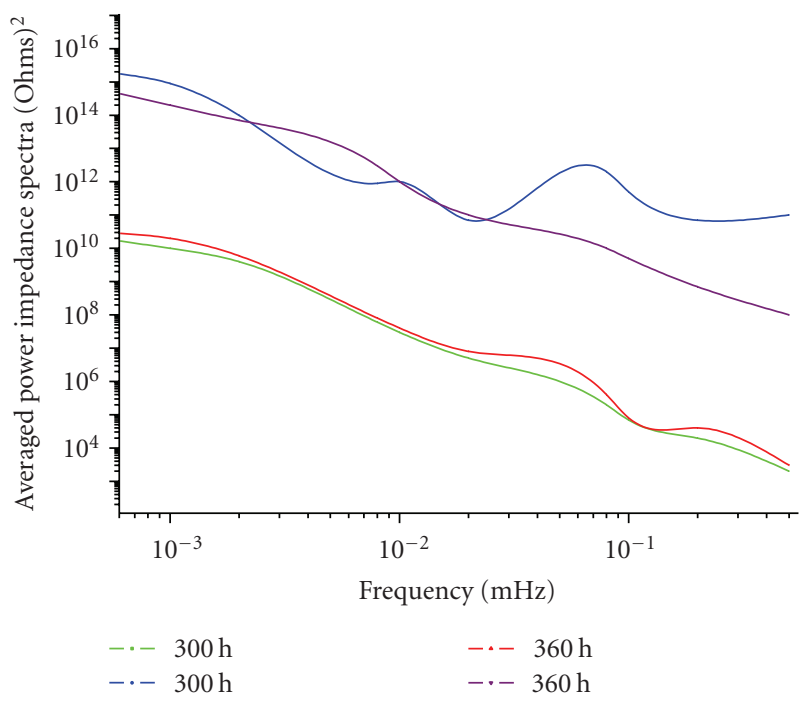

(d) 300 and $360 \mathrm{~h}$

FIgURe 10: Power noise impedance spectra for the coating with $5 \%$ silica particles without and with $3.1 \mathrm{ppm} \mathrm{Fe}\left(\mathrm{NO}_{3}\right)_{3}$ inhibitor concentration for different times of immersion.

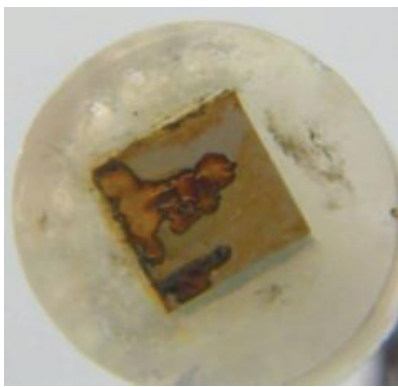

(a)

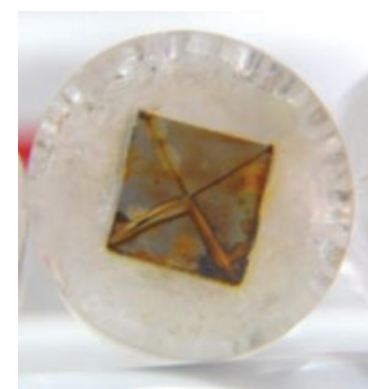

(b)

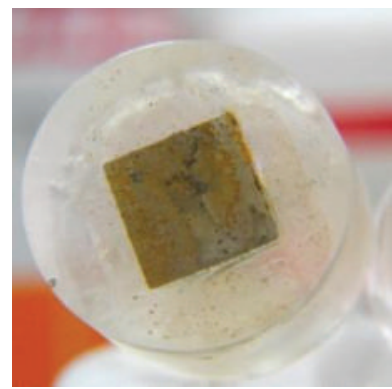

(c)

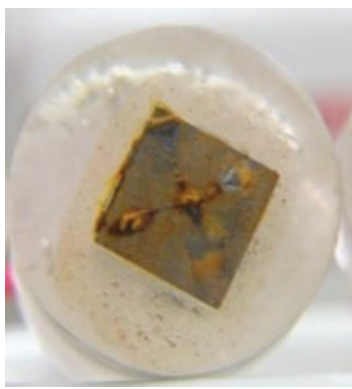

(d)

FIGURE 11: Mild steel coated samples after immersion test showing (a) coated surface and (b) scratched coated surface without silica particles and inhibitor, (c) coated surface and (d) scratched coated surface with silica particles and $3.1 \mathrm{ppm} \mathrm{Fe}\left(\mathrm{NO}_{3}\right)_{3}$ inhibitor concentration. 
100 times, as compared to a "coating only" corrosion control condition.

\section{Acknowledgments}

The authors expressed their gratitude to CONACYT for the financial support granted for the development of this paper and to Dr. Linda Uruchurtu for the revision of the paper.

\section{References}

[1] M. L. Zheludkevich, J. Tedim, C. S. R. Freire et al., "Selfhealing protective coatings with "green" chitosan based prelayer reservoir of corrosion inhibitor," Journal of Materials Chemistry, vol. 21, no. 13, pp. 4805-4812, 2011.

[2] R. L. Cook and A. W. Myers, "Nanotechnology applications in coatings," Nanoparticle Surface Modification for Advanced Corrosion Inhibiting Coatings, vol. 1008 of ACS Symposium Series, chapter 5, American Chemical Society, 2009.

[3] C. Challener, "The intelligence behind smart coatings," JCT CoatingsTech, vol. 3, no. 1, pp. 50-55, 2006.

[4] W. Feng, S. H. Patel, M. Y. Young, I. L. Zunino, and M. Xanthos, "Smart polymeric coatings_recent advances," Advances in Polymer Technology, vol. 26, no. 1, pp. 1-13, 2007.

[5] W. Li and L. M. Calle, "Smart coating for corrosion sensing and protection," in Proceedings of the US Army Corrosion Summit, Clearwater Beach, Fla, USA, February 2006.

[6] S. J. Davis and J. F. Watts, "Interfacial chemistry of adhesive joint failure: an investigation by small area XPS, imaging XPS and TOF-SIMS," Journal of Materials Chemistry, vol. 6, no. 3, pp. 479-493, 1996.

[7] N. A. Allsop, M. R. Bowditch, N. F. C. Glass, A. E. Harris, and P. M. O'Gara, "Thermal analysis in the development of self validating adhesives," Thermochimica Acta, vol. 315, no. 1, pp. 67-75, 1998.

[8] E. N. Brown, S. R. White, and N. R. Sottos, "Microcapsule induced toughening in a self-healing polymer composite," Journal of Materials Science, vol. 39, no. 5, pp. 1703-1710, 2004.

[9] D. G. Shchukin, M. Zheludkevich, K. Yasakau, S. Lamaka, M. G. S. Ferreira, and H. Möhwald, "Layer-by-layer assembled nanocontainers for self-healing corrosion protection," Advanced Materials, vol. 18, no. 13, pp. 1672-1678, 2006.

[10] A. N. Khramov, N. N. Voevodin, V. N. Balbyshev, and M. S. Donley, "Hybrid organo-ceramic corrosion protection coatings with encapsulated organic corrosion inhibitors," Thin Solid Films, vol. 447-448, pp. 549-557, 2004.

[11] M. L. Zheludkevich, R. Serra, M. F. Montemor, K. A. Yasakau, I. M. M. Salvado, and M. G. S. Ferreira, "Nanostructured solgel coatings doped with cerium nitrate as pre-treatments for AA2024-T3 Corrosion protection performance," Electrochimica Acta, vol. 51, no. 2, pp. 208-217, 2005.

[12] R. G. Buchheit, S. B. Mamidipally, P. Schmutz, and H. Guan, "Active corrosion protection in Ce-modified hydrotalcite conversion coatings," Corrosion, vol. 58, no. 1, pp. 3-14, 2002.

[13] R. B. Leggat, S. R. Taylor, W. Zhang, and R. G. Buchheit, "Corrosion performance of field-applied chromate conversion coatings," Corrosion, vol. 58, no. 3, pp. 283-291, 2002.

[14] W. Meier, "Polymer nanocapsules," Chemical Society Reviews, vol. 29, no. 5, pp. 295-303, 2000.

[15] C. S. Peyratout, H. Möhwald, and L. Dähne, "Preparation of photosensitive dye aggregates and fluorescent nanocrystals in microreaction containers," Advanced Materials, vol. 15, no. 20, pp. 1722-1726, 2003.

[16] S. Förster and T. Plantenberg, "From self-organizing polymers to nanohybrid and biomaterials," Angewandte Chemie International Edition, vol. 41, no. 5, pp. 689-714, 2002.

[17] A. Manna, T. Imae, K. Aoi, M. Okada, and T. Yogo, "Synthesis of dendrimer-passivated noble metal nanoparticles in a polar medium: comparison of size between silver and gold particles," Chemistry of Materials, vol. 13, no. 5, pp. 1674-1681, 2001.

[18] A. Sunder, M. Krämer, R. Hanselmann, R. Mülhaupt, and H. Frey, "Molecular nanocapsules based on amphiphilic hyperbranched polyglycerols," Angewandte Chemie International Edition, vol. 38, no. 23, pp. 3552-3555, 1999.

[19] X. Lu and Z. Xin, "Preparation and characterization of micron-sized polystyrene/polysiloxane core/shell particles," Colloid and Polymer Science, vol. 284, no. 9, pp. 1062-1066, 2006.

[20] C. I. Zoldesi, C. A. Van Walree, and A. Imhof, "Deformable hollow hybrid silica/siloxane colloids by emulsion templating," Langmuir, vol. 22, no. 9, pp. 4343-4352, 2006.

[21] G. Schneider and G. Decher, "From functional core/shell nanoparticles prepared via layer-by-layer deposition to empty nanospheres," Nano Letters, vol. 4, no. 10, pp. 1833-1839, 2004.

[22] M. Hernández, J. Genescá, J. Uruchurtu, and A. Barba, “Correlation between electrochemical impedance and noise measurements of waterborne coatings," Corrosion Science, vol. 51, no. 3, pp. 499-510, 2009.

[23] E. Abdullayev, R. Price, D. Shchukin, and Y. Lvov, "Halloysite tubes as nanocontainers for anticorrosion coating with benzotriazole," ACS Applied Materials \& Interfaces, vol. 1, no. 7, pp. 1437-1443, 2009.

[24] J. Uruchurtu-Chavarín and J. M. Malo, "5 Electrochemical noise as a powerful electrochemical technique for corrosion studies," Research Trends: Trends in Corrosion Research, vol. 2, pp. 49-58, 1997.

[25] D. V. Andreeva and D. G. Shchukin, "Smart self-repairing protective coatings," Materials Today, vol. 11, no. 10, pp. 2430, 2008.

[26] M. Hernández, J. Genescá, J. Uruchurtu, F. Galliano, and D. Landolt, "Effect of an inhibitive pigment zinc-aluminumphosphate (ZAP) on the corrosion mechanisms of steel in waterborne coatings," Progress in Organic Coatings, vol. 56, no. 2-3, pp. 199-206, 2006.

[27] M. A. Gonzalez-Nunez and J. Uruchurtu-Chavarin, "R/S fractal analysis of electrochemical noise signals of three organic coating samples under corrosion conditions," Journal of Corrosion Science and Engineering, vol. 6, pp. 1-5, 2003.

[28] J. M. Bastidas and J. M. Malo, "Electrochemical Noise (1/f) in the study of the corrosion inhibitor efficiency," Revista de Metalurgia, vol. 21, no. 6, pp. 337-341, 1985.

[29] E. Sarmiento, J. G. González-Rodriguez, J. Uruchurtu, O. Sarmiento, and M. Menchaca, "Fractal analysis of the corrosion inhibition of carbon steel in a bromide solution by lithium chromate," International Journal of Electrochemical Science, vol. 4, no. 1, pp. 144-155, 2009.

[30] E. Almeida, D. Santos, and J. Uruchurtu, "Corrosion performance of waterborne coatings for structural steel," Progress in Organic Coatings, vol. 37, no. 3-4, pp. 131-140, 1999. 

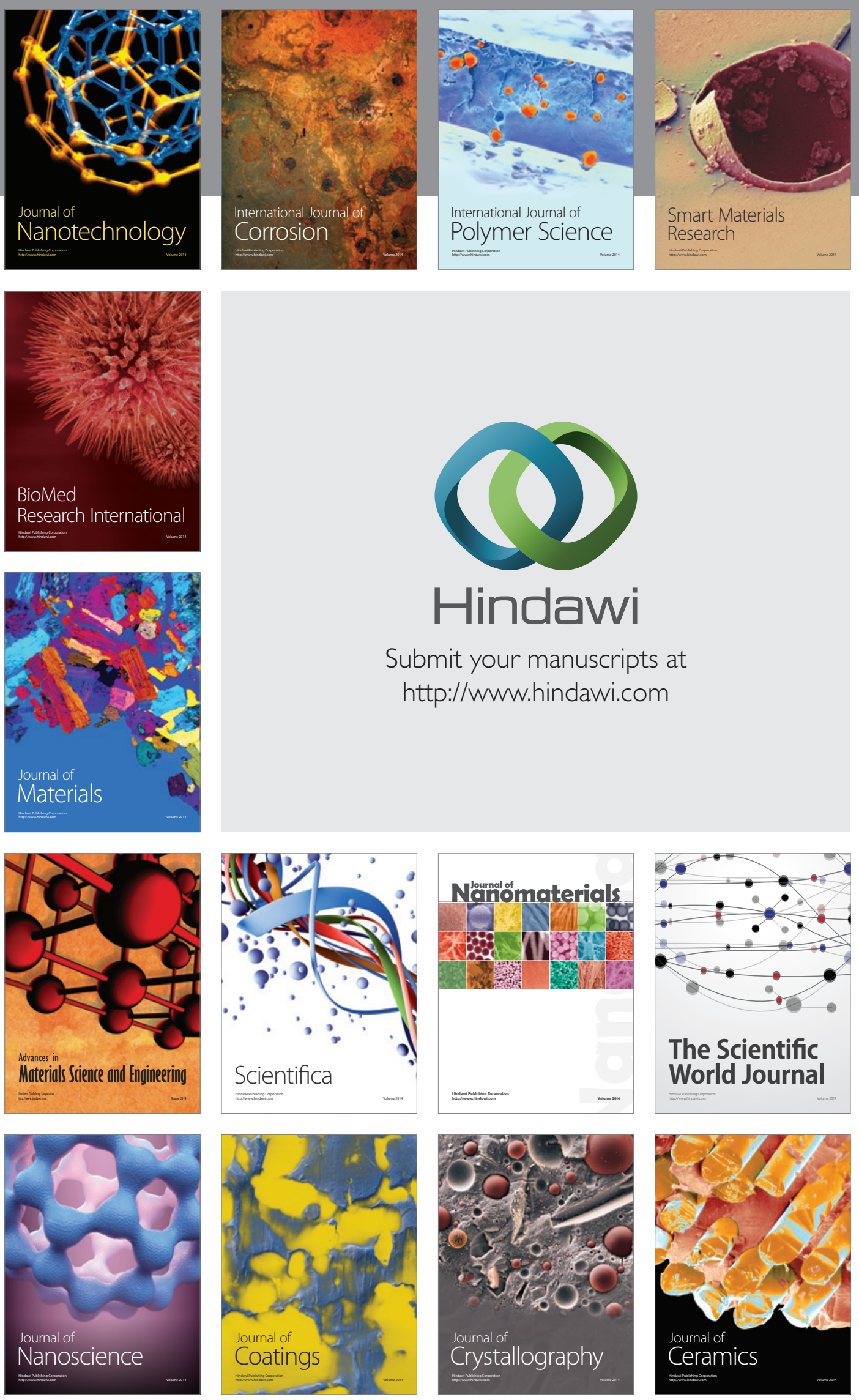

The Scientific World Journal

Submit your manuscripts at

http://www.hindawi.com

\section{World Journal}

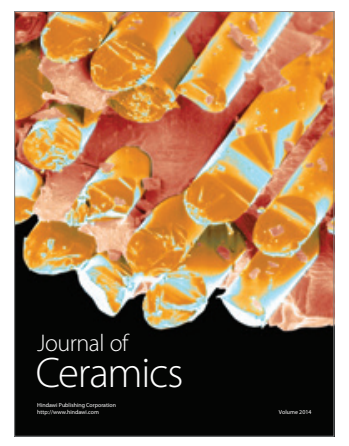

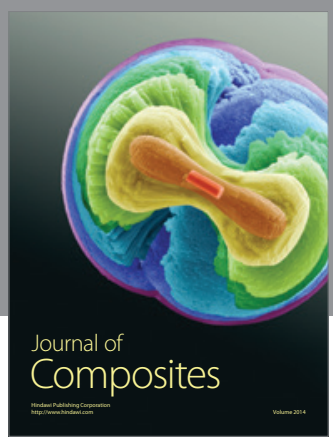
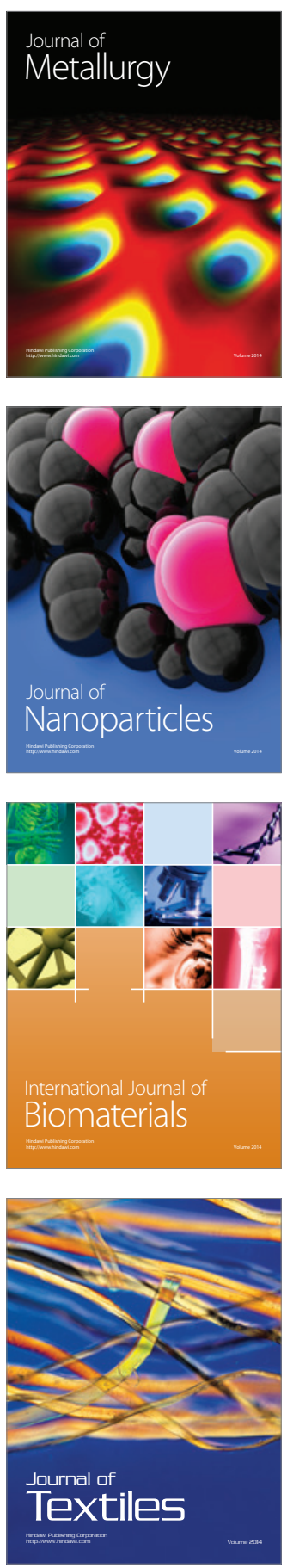